\title{
Anna Cornagliotti, Artù settimo Prode di Sebastien Mamerot
}

\section{Stefania Vignali}

\section{(2) OpenEdition}

\section{Journals}

\section{Edizione digitale}

URL: http://journals.openedition.org/studifrancesi/34406

DOI: 10.4000/studifrancesi.34406

ISSN: 2421-5856

\section{Editore}

Rosenberg \& Sellier

\section{Edizione cartacea}

Data di pubblicazione: 1 novembre 2005

Paginazione: 393

ISSN: 0039-2944

\section{Notizia bibliografica digitale}

Stefania Vignali, «Anna Cornagliotti, Artù settimo Prode di Sebastien Mamerot», Studi Francesi [Online], 146 (XLIX | II) | 2005, online dal 30 novembre 2015, consultato il 18 avril 2021. URL: http:// journals.openedition.org/studifrancesi/34406 ; DOI: https://doi.org/10.4000/studifrancesi.34406

Questo documento è stato generato automaticamente il 18 avril 2021.

\section{(c) $(7)$}

Studi Francesi è distribuita con Licenza Creative Commons Attribuzione - Non commerciale - Non opere derivate 4.0 Internazionale. 


\title{
Anna Cornagliotti, Artù settimo Prode di Sebastien Mamerot
}

\author{
Stefania Vignali
}

\section{NOTIZIA}

ANNA CORNAGLIOTTI, Artù settimo Prode di Sebastien Mamerot, in Favola, Mito e altri saggi di letteratura e filologia in onore di Gianni Mombello, cit., pp. 389-422.

1 La mancanza di uno studio esaustivo relativo all'identificazione delle fonti sfruttate da Sebastien Mamerot nella stesura della Histoire des neuf preux et des neuf preuses (tramandataci dall'unico ms. 2578 conservato alla Österreichische Nationalbibliothek di Vienna) conduce l'autrice a circoscrivere il suo contributo allo studio minuzioso del ruolo conferito ad Artù all'interno dell'opera.

2 Confutando la tesi proposta da R. Trachsler, secondo la quale Mamerot sarebbe stato un semplice traduttore dell'enciclopedica Historiae Regum Britanniae, Cornagliotti mostra attraverso numerosi esempi come le fonti dalle quali l'autore ha attinto siano state numerose e come la sua compilazione sia stata certamente preceduta non solo da un'abile ricognizione di testi di materia arturiana in latino ed in volgare, ma, là dove si presenti una traduzione del texte-source, la correzione per mano del traduttore è fortemente ipotizzabile. La dimostrazione della varietà delle fonti, fondata sulla comparazione di numerosi frammenti di testo, è paziente e dettagliata. Il contributo propone infine l'edizione del ritratto di re Artù, settimo medaglione presente nel ms. 